\title{
MEANING AND PRAGMATISM: THE VIOLATIONS OF MAXIMS IN TRUTH ANALYSIS IN THE TV SERIES LIE TO ME (2010)
}

\author{
Regina Vika
}

\begin{abstract}
Grice proposed the Cooperative Principle, which contains four maxims, as an element in communication. When the four maxims is violated, it means that the speaker has did something to create a condition, particularly in crime investigation. The truth condition, which has relation to lie, is frequently happen in people's life. Lie can be studied pragmatically within the relevance theory. The focus of this study is to analyze the existence of which maxims may be violated in a lie. The study on the characters in TV series Lie to Me shows that each character violates certain maxims in the same time. The reason for selecting Lie to $M e$, there are various ways and reasons to violate the maxims. The finding of this study that one from four maxims is rarely violated because of a possibility reason. However, it cannot be justified that people are lying means they feel guilty toward crime action. Also, it can be helpful to understand what is the Cooperative Principle theory for linguistic learners.
\end{abstract}

\section{Keyword}

Gricean maxims, the Cooperative Principle, Lie to me, violation of maxims

\section{INTRODUCTION}

Communication is a verbal skill to communicate with each other, and this makes it an important role in every aspects of a human's life. Communication itself consists of sentences of a particular language, which is used by speakers to express their feelings. However, if a user does not understand the language to communicate with other people, the purpose of the communication cannot be accomplished. When people communicate, they create various conditions; depending on the kind of topic they are talking about. The way to express what people want to say to the others is by saying it directly and indirectly, which can be successful or not. Indirectness occurs when an utterance fails to express, and then a speaker uses implication in the utterance to fulfill a certain purpose. People will look for information about a meaning that comes from the context of utterance (Jaszczolt 03), it means that the hearer draws an assumption from the speaker's intentions and builds the implied meaning. 
In communication, the speaker and the hearer have to contribute and respond to the information that has been discussed, and this is supposed to be a useful information to them. The rule is that they have to understand each other's utterance. To reach the purpose of communication, both of speaker and hearer have to fulfill the Cooperative Principle, which according to Grice consists of four maxims (1975). The maxims are the Maxim of Relevance, the Maxim of Quality, the Maxim of Quantity, and the Maxim of Manner. Grice defines the Cooperative Principle, as "making your conversational contribution such as is required, at the stage at which it occurs, by the accepted purpose or direction of the talk exchange in which you are engaged" (1975). Below are the principles of the four maxims that Grice created to make sure that the utterance connects what we say and the things itself.

First, the maxim of quantity, it means that a speaker should be as informative as is required. As a result, the speaker does circumlocution or not being straight to the point. In addition, the speaker should not give information too much or too little. When people do not give enough information, it means that the hearer may not be able to identify what they are talking about. In contrast, people who give too much information will make the hearer boring. They also have a tendency to repeat certain words because the speaker wants to make circumlocution or not to the point. The purpose of this maxim is to present that a statement is strong or informative. For example

Tim: You know, Barry, this was a very strange way to meet, but I think everything happens for a reason.

Barry: Wow! Wow! Did you just make that up?

Tim: Yeah!

Barry: 'Everything happens for a reason!' I like that.

Tim: Thanks, Anyway! Tomorrow, I'm having dinner with some friends.

Barry: Are you? Oh, that's incredible. Congratulations!

Tim: I was wondering. Would you like to join us?

\section{(Khosravizadeh 04)}

Second, the maxim of Quality, it means that a speaker is expected to be sincere because the speaker is not assumed to say anything that it believes to be false or lack of evidence. Some speakers like to draw their hearer's attention to the fact that they are only saying what they believe to be true, and that they lack adequate evidence. People who violate maxim of quality will deliver a statement by using sarcastic tone to express a statement, which is different from the literal meaning to tease others. It can show that the speaker denies or distorts information. For example:

Teacher: Wow! You're such a punctual fellow! Welcome to the class.

Student: Sorry sir! It won't happen again.

(Khosravizadeh 09) 
The maxim of Relevance means that a speaker is assumed to be saying information that is relevant to what has been said before. During the conversation, a hearer compares new information with knowledge that the hearer already has, focus on the information, which is most related to the knowledge, and lastly make an assumption about the speaker's intention by processing the information ( $\mathrm{Hu} \mathrm{05).} \mathrm{As} \mathrm{a} \mathrm{result,} \mathrm{the} \mathrm{speaker} \mathrm{does}$ the wrong causality to support he or she words because he or she wants to avoid about the topic. For example:

Bob: What were you and Anna talking about? You were looking at me all the time! Marry: Oh, well... why don't we go get something to drink?

Bob: Are you avoiding this conversation? There has to be something going on about me! Why aren't you brave enough to tell me?

Marry: Well, you know... they think that you are the one who stole that money.

\section{(Khosravizadeh 09)}

Fourth, the maxim of Manner means that a speaker uses ambiguous language to exaggerate information. Moreover, the speaker uses slang in front of people who do not understand it. The speaker is expected to say something briefly and in an orderly manner. For example:

Wife: Darling..... What's the story with that new watch on your wrist?

Husband: Oh, this watch you're talking about! I knew it... I told my boss that my wife would be curious when she sees it. Oh, honey you have no idea how much they're satisfied with my performance, lately!

\section{(Khosravizadeh 03)}

Grice had already made the guidelines for the speaker to be cooperative in having the conversation. When a speaker violates a maxim, the speaker deliberately ceases to apply the maxims to persuade a hearer to infer the hidden meaning behind the utterances. Nevertheless, violation of the maxims is what happens when people are telling a lie because the conversation between the speaker and the hearer cannot be successful, and they will not understand each other. A lie takes an importance part in communicative competence, and an incorporates as a natural way to survive and cover up a secret from the speaker, which is the hearer only catch up the surface meaning of the speaker's words. As a result, there is always a different meaning between what it is said and what is meant, which is called as utterance (Jaszczolt 03). It is important to understand what an utterance is because the utterance always gives a contextual implicit and explicit meaning, the meanings built have a relation with truth-condition, it is to find out that a given suspect is guilty (or not guilty), and responsible or not for something (Dutra 13). Truth is necessary to connect evidence with the verdict given. By knowing a contextual meaning of an utterance, it must be easier to find out what is exactly said 
(the proposition of the conversation) (Malinowski 07). The procedure of an utterance is depicted in the following diagram:

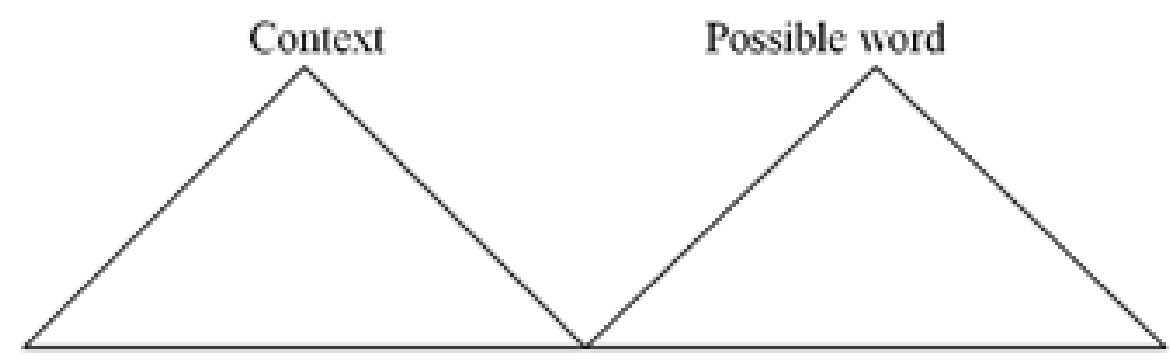

\section{$\begin{array}{lll}\text { Utterance } & \text { Proposition } & \text { Meaning }\end{array}$}

Figure 1. The Structure of Interpreting Sentences (Malinowski 07)

First, the hearer hears an utterance, and then find out what exactly is said (proposition). To understand that a context is needed by looking at the appropriate possible words between utterances and proposition this has a context. Then, between proposition and meaning, there is a possibility, which comes from the speaker. Those aspects cannot be separated to each other. As a result, the hearer will be able to establish the meaning of the given sentence. (See figure 1)

In recent years, a research on truth analysis, the particular view of linguistic meaning and of blame for violation that relies on intention-seeking, has been done several times before. However, some of the previous researches only discussed the theory of truth analysis without giving specific data to support it. One of the researches discussed the violation of maxims in comedy. The purpose of the research was to examine how violation could be also used to create humor. It is common for comedy genre creates violation to reach certain purpose, and the same thing applies in truth analysis. Therefore, it has a relation with my topic about truth analysis based on utterance because it shows the correlation between what is said and what is implicated. Truth-conditional presents the best-developed approach to the sentence meaning (Jaszczolt 02). To analyze that, a structure is not only standard truth-conditional analysis, but people also have to look deeper information about meaning from utterance. The pragmatic theory contributes to the truth-conditional content, so it is really interesting to see that truth condition comes from utterances, not sentences.

In the real life, people have a tendency to lie because they believe that a lie is the natural tool to survive and to avoid them from anything that may put them in an inappropriate condition (qtd. in Tupan 02), and then break the Cooperative Principle. Since, people do not have a natural ability to predict which story is true or not, it is not easy to determine specific attitudes as a lie. As a result, an utterance is required to understand that. This is pictured in the American TV series entitled Lie to Me (2010). It is 
about crime investigation set in America. Lie to Me is centered on four characters: Dr. Cal Lightman, Dr. Foster, Eli Loker, and Ria Torres, which have different skills in "reading" people when they are lying. This series helps to understand that in crime investigation the truth can be revealed from utterance, which happens in an investigation itself. Most suspects often violated the maxims in their lie. Lie to Me can be relevant sample as a case study because this series consists with many dialogues of liars. I choose Lie to Me because it is one of the most popular series, and Lie to Me won two awards at the 37th People's Choice Awards in 2011. Besides that, the main characters were inspired on real characters, so the utterances on the series, which came from suspects, were happen in real investigation. Truth analysis may not popular, but I want to analyze something new by using that TV series. I argue that when people lie the purpose can be good or bad for both the speakers and the hearers. I believe liars have certain way or pattern to violate the maxims, which shows the distance from the truth. I will focus only on the dialogues, which have a lot of violation during investigation.

In this study, I will use the Conversational Maxims suggested by Grice (1975). I will collect the data from the movie series on television entitled Lie to Me (2010) which consists with utterance from liars. I will pick five episodes to analyze, then, I will classify the violations of maxim per episode. I will mention the conversation, and then I will identify the findings and the reason why the speaker violated the maxims. In addition, this study will be helpful to understand Grice's theory, the Cooperative Principle, especially to improve the understanding of maxims violation from utterances specifically when a person lies.

\section{METHODOLOGY}

I will choose five episodes (Better Half, Love Always, Undercover, Honey, Truth or Consequences) from season one and two, which contains interesting problems, conflicts, and lies among the characters. I chosen those episodes because the characters who violated the maxims did not mean that they were suspects of the crime, also the episodes contain unordinary stories with complicated cases. I will use descriptive study to analyze the utterances. The data will be indentified by using Conversational Maxims suggested by Grice (1975). First, I will classify the violations by using table consists of speaker, utterances, and checklist of violations. In the table, I will use acronym QN which stands for quantity, QL for quality, RL for relevance, and MN for manner.

\section{DISCUSSION}

As I have mentioned before, the aim of this research is to find the violations of maxims, which are caused by the characters in TV series Lie to Me. The data were collected by identifying the conversations that contained a lie. The characters have different purposes when violating the maxims. The speaker did want to hurt someone 
feeling, or the speaker wanted to build someone's belief, so he or she could convince the hearer with no doubt. This can be seen in the following excerpts:

\section{Excerpt 1:}

The Lightman Group was hired to help with an arson case, which contained with an affair conflict between the suspect and the victim of arson case.

(Setting: Dr. Lightman's office - In the investigation room, a woman and her son were waiting Dr. Lightman. Her son was drawing something while a woman watched. Dr. Lightman came.)

Dr. Lightman: What was your relationship with the man that your son has accused?

A Woman: Excuse me?

Dr. Lightman: Were you having an affair with Jack Gracia?

A Woman: How dare you accuse me of having an affair in front of my son! (angry tone)

Dr. Ligthman: Are you having an affair with Jack Gracia?

A Woman: I am getting my son and I am going (angry tone and pointed her finger to Dr. Ligthman)

(Lie to Me,"Better Half", 16:10)

\begin{tabular}{|l|l|c|c|c|c|}
\hline Speaker & Utterances & QN & QL & RL & MN \\
\hline A women & $-\quad$ Excuse me? & $\sqrt{ }$ & $\sqrt{ }$ & $\sqrt{ }$ & \\
& $-\quad \begin{array}{l}\text { How dare you accuse me of having } \\
\text { an affair in front of my son! }\end{array}$ & $\sqrt{ }$ & $\sqrt{ }$ & $\sqrt{ }$ & \\
& & & & \\
\hline
\end{tabular}

Table 1

Note: $\mathrm{QN}=$ Quantity, $\mathrm{QL}=$ Quality, $\mathrm{RL}=$ Relevance, $\mathrm{MN}=$ Manner

It can be seen that the woman did multiple violations. She violated the maxim of quantity, maxim of quality, and maxim of relevance. At the beginning of the conversation, Dr. Lightman asked her about the relationship, but she answered with a question answer, which is the speaker did not to the point and informative (violated the maxim of quantity). She did not answer the question by saying yes or no; instead, she was angry because Dr. Lightman asked in front of her son. It shows that she denied something about the truth (violated maxim of quality) by switch the topic. She wanted to convince Dr. Lightman by using angry words which is make the answer unmatched with the topic 'I am getting my son and I am going' (violated the maxim of relevance). Dr. Lightman asked the same questions until three times, but the woman covered the truth, and focused that the questions were impolite to ask in front of her son. Actually, it is obvious that the woman were having an affair, but those answers were safe answers to hide the truth that the speaker felt. There are some possibilities why the woman did want to tell the truth. She made an image that she did not guilty, though, she lied because she did want to tell the truth in front of her son. Overall, the woman did three violations to save her secret, and to protect herself. 


\section{Excerpt 2:}

(Setting: Dr. Lightman's office - In the room investigation, Dr. Lightman asked again about the affair)

Dr. Ligtman: So, you have an affair?

Woman: Every minute with Jack Gracia was a chance to be with somebody who did not know me or my problems.

Dr. Lightman: Maybe you did not leave Jack Gracia. Maybe he left you.

Woman: What? (shock tone)

Dr. Lightman: You hated him.

Woman: You think that I had burn down my own house? (angry tone)

(Lie to Me,"Better Half", 16:58)

\begin{tabular}{|l|l|c|c|c|c|}
\hline Speaker & Utterances & QN & QL & RL & MN \\
\hline Woman & $\begin{array}{l}\text { Every minute with Jack Gracia was a } \\
\text { chance to be with somebody who did } \\
\text { not know me or my problems } \\
\text { You think that I had burn down my } \\
\text { own house? }\end{array}$ & $\sqrt{ }$ & $\sqrt{ }$ & & $\sqrt{ }$ \\
& & & & \\
\hline
\end{tabular}

Table 2

Note: $\mathrm{QN}=$ Quantity, $\mathrm{QL}=$ Quality, $\mathrm{RL}=$ Relevance, $\mathrm{MN}=$ Manner

When the woman answered the first question, she showed an action that she did not want to be cooperating by saying uninformative answer (violated the maxim of quantity). She also answered with ambiguous answer (violated the maxim of manner), which was the affair may happen. 'Every minute with Jack Gracia was a chance to be with somebody who did not know me or my problems', It clearly can be seen that the answer is not relevant because there is something hiding. She did not answer strictly or deny the affair. She also explained unnecessary information too much (violated the maxim of quantity). Dr. Lightman needed to reveal the love affair because it might have a relation to the revenge in love affair or not. The whole answers were unnecessary answers. Then, she came up with angry answer, 'You think that I had burn down my own house?', she blamed herself by saying something that was believed to be false (violated the maxim of quantity), so her expectation that Dr. Lightman was wrong about her to think that she had burnt the house. However, she used wrong causality to show that the accusation was completely wrong (violated the maxim of relevance). She dragged a conclusion, which had not been mentioned by Dr. Lightman. Blaming is one of the ways to avoid an accusation. For her, it was not a big deal to answer irrelevant as long as she did not accuse as a suspect. The whole answers do not show that she was the suspect or not, but it can be seen that she hide something to save herself. The woman did two times in the maxim of quality, two times in the maxim quantity, and one time in the maxim of manner. 


\section{Excerpt 3:}

A controversial South Korean ambassador was presumed to be an assassination target at his son's state wedding. The Lightman team was sent to prevent the murder. The son was shot instead and Lightman exposed long-held family secrets and lies in order to identify the killer

(Setting: Ballroom in a wedding - Son of Prime Minister was shot, and Dr. Lightman was looking for the murderer. He investigated the Prime Minister)

Dr. Lightman: Why would an official protect his bodyguard? Are they brothers?

Prime Minister: Ridiculous. (grin face)

Dr. Lightman: Mistakes happen. Is he your son?

Prime Minister: You were hired to protect my family, not look into our private life.

Dr. Lightman: So, he is your son.

Prime Minister: I did not say that.

(Lie to Me, "Love Always", 29:53)

\begin{tabular}{|l|l|l|l|l|l|}
\hline Speaker & Utterances & QN & QL & RL & MN \\
\hline Prime Minister & $\begin{array}{l}\text { Ridiculous. } \\
\text { You were hired to protect my family, }\end{array}$ & $\sqrt{ }$ & $\sqrt{ }$ & $\sqrt{ }$ & \\
& $\begin{array}{l}\text { not look into our private life. } \\
\text { I did not say that }\end{array}$ & $\sqrt{ }$ & $\sqrt{ }$ & $\sqrt{ }$ & \\
\hline
\end{tabular}

Table 3

Note: $\mathrm{QN}=$ Quantity, $\mathrm{QL}=$ Quality, $\mathrm{RL}=$ Relevant, $\mathrm{MN}=$ Manner

The Prime minister did multiple violations. In the first question, when he answered 'Ridiculous' showed that the answer are not to the point and uninformative (violated the maxim of quantity), he denied something by using surprised word that might not have happened in his life (violated the maxim of quality). Then, he denied again, by answering 'You were hired to protect my family, not look into our private life' (violated the maxim of quality). He talked too much, which was the answer only yes or no answer (violated the maxim of quantity). He explained unnecessary information to the fact (violated the maxim of relevant). Nevertheless, the Prime Minister did not deny the fact directly that the bodyguard was his son (the maxim of quantity). 'I did not say that' means he used ambiguous words (violated maxim of manner). He may wanted to admit the fact, but he did not want others to know about that because it would make bad his reputation as a Prime Minister. As a result, he lied to save his image. He focused on positive answer to express his attention, which was believed to be false by Dr. Lightman. The reason he did not admit it because he was afraid that people would judge him by having other son, which was not from his wife. The Prime Minister violated three maxims, three times in the maxim of quantity, three times in the maxim of quality, and two times in the maxim of relevance. 


\section{Excerpt 4:}

(Setting: Hospital - Wife of Prime Minister's Son was waiting her husband. Dr. Lightman and Dr. Foster came)

Dr. Foster: But it looks like whoever shot your husband.... It does not look like that anymore. Did he ever mention anyone threatening him?

Wife of Prime Minister's Son: Threatening him? Uh, no. (thinking face)

Dr. Lightman: What were you just thinking?

Wife of Prime Minister's Son: Excuse me?

Dr. Lightman: Something just went through your mind.

(Lie to Me, "Love Always", 16:20)

\begin{tabular}{|l|l|l|l|l|l|}
\hline Speaker & Utterances & QN & QL & RL & MN \\
\hline $\begin{array}{l}\text { Wife of Prime } \\
\text { Minister's Son }\end{array}$ & $-\quad$ Threatening him? Uh, no & $\sqrt{ }$ & & $\sqrt{ }$ & \\
\hline
\end{tabular}

Table 4

Note: $\mathrm{QN}=$ Quantity, $\mathrm{QL}=$ Quality, $\mathrm{RL}=$ Relevant, $\mathrm{MN}=$ Manner

The wife of the Prime Minister's son only violated two maxim, the maxim of quantity and the maxim of relevance. In the first question, she violated the maxim of quantity by repeating certain words, but she answered it to make sure Dr. Lightman and Dr. Foster that she did not know about anything. In the second question, she answered with question answer, which is not relevant to the question. It shows that she hide something. Moreover, wife of prime minister's son wanted to make sure the person who shot her husband. As a result, she lied because she might know who was trying to kill, but she did not sure about the suspect, and better to keep it first.

\section{Excerpt 5:}

Dr. Lightman investigated a controversial case about a cop who shot a teenager and the threat of a terrorist attack

(Setting: Police Station - Room Investigation. A cop was a suspect for a murder)

Dr. Lightman: Did you plant the gun?

Cop: Excuse me? Did I plant the gun? No, I did not. (low pitch, he seemed that he did not sure with his answer)

Dr. Lightman: Well, you said that Adam Duke was A terrorist You are giving bad information to the FBI's.

Cop: You saying I am Al Qaeda? I got picture of Osama in my wallet? (angry tone)

Dr. Lightman: I did not say it.

(Lie to Me, "Undercover", 07:50) 


\begin{tabular}{|l|l|l|l|l|l|}
\hline Speaker & Utterances & QN & QL & RL & MN \\
\hline Cop & $-\begin{array}{l}\text { Excuse me? Did I plant the gun? No, I } \\
\text { did not. }\end{array}$ & $\sqrt{ }$ & $\sqrt{ }$ & $\sqrt{ }$ \\
& $\begin{array}{l}\text { You saying I am Al Qaeda? I got } \\
\text { picture of Osama in my wallet? }\end{array}$ & $\sqrt{ }$ & $\sqrt{ }$ & $\sqrt{ }$ & $\sqrt{ }$ \\
& & & & \\
\hline
\end{tabular}

Table 5

Note: $\mathrm{QN}=$ Quantity, $\mathrm{QL}=$ Quality, $\mathrm{RL}=$ Relevant, $\mathrm{MN}=$ Manner

From the cop utterances, he violated the maxim of quantity and quality by giving uninformative and sarcastic answers to deny the truth. 'Did I plant the gun? No, I did not', the speaker repeated the same question with low pitch (violated the maxim of quantity), that had been asked for shows that he answered it with lack of confidence, and he did not expect Dr. Lightman could think about that. He answered by using question answer, but then he answered, 'No, I did not.' It is obvious that he surprised with the question, yet he did not prepare to lie well. He denied and distorted information (violated the maxim of quality). When he violated the maxim of manner, the cop used sarcastic answer to make ambiguous statement, 'You saying I am Al Qaeda? I got picture of Osama in my wallet?'. In fact, Dr. Lightman did not saying anything which had relation to the Al Qaeda, in contrast, the cop seemed that he had revealed the truth unconsciously. By violating those maxims, the cop wanted to build Dr. Lightman's belief that he was never be a part of a murder, and he felt offended with the accusation. This excerpt shows that the character violated all maxims in seven times. Each maxim was violated two times, except the maxim of relevance.

\section{Excerpt 6:}

Dr. Lightman and team found out that Matheson was actually innocent and that his wife was actually killed by a loan shark, Mike.

(Setting: Dr. Lightman's office - Room Investigation. Dr. Foster was investigating a suspect from murder case in apartment)

Dr. Foster: He said you killed Connie? Did you?

Mike: I am not even gonna dignify that with a comment.

Dr. Foster: She recorded a phone conversation she had with you trying....... you went over to Connie's apartment looking for that recorded. Did not you, Mike?

Mike: It is like I told the black dude. I have never been to her place before.

Dr.Foster: You turned the place upside down, and you found that digital recorder.

Mike: Man, you have in fantasyland, lady. You know that? (he showed tease face)

Dr. Foster: She was gonna show it your wife, and you lost your temper.

(Lie to Me, "Honey", 34:20) 


\begin{tabular}{|l|l|l|l|l|l|}
\hline Speaker & Utterances & QN & QL & RL & MN \\
\hline Mike & $\begin{array}{l}\text { Iam not even gonna dignify that with a comment } \\
\text { Man, you have in fantasyland, lady. You know }\end{array}$ & $\sqrt{ }$ & $\sqrt{ }$ & $\sqrt{ }$ \\
& \begin{tabular}{l} 
that? \\
\hline
\end{tabular} & & & \\
\hline
\end{tabular}

Table 6

Note: $\mathrm{QN}=$ Quantity, $\mathrm{QL}=$ Quality, $\mathrm{RL}=$ Relevant, $\mathrm{MN}=$ Manner

When Dr. Foster asked, Mike was uninformative and not to the point (violated the maxim of quantity). However, Dr. Foster knew, and she kept asking by giving details from the incident. It also can be seen from two utterances that Mike wanted to protect his self by avoiding the truth (violated the maxim of relevant). He did not want to answer because he wanted other people believe that killing people means impropriate behavior, which was contrast with his behavior. When Dr. Foster kept talking about the detail of murder, Mike violated the maxim of quality by using sarcastic statement to refer that the speaker expressed something that he wanted to deny, 'Man, you have in fantasyland, lady. You know that?' Mike's expectation that Dr. Foster would believe he had nothing to do with the murder, so he tried to calm his nervous when he was lying by using positive words such as, fantasyland and dignify. He hid the truth because he did not want to blame. This character violated three maxims, which are the maxim of quantity, maxim of quality, and maxim of relevance. Each maxim was violated two times.

\section{Excerpt 7:}

Foster and Loker traveled to a religious compound to determine whether its claim of IRS exemption was valid. They believed that the head of the compound was holding the women against their will

(Setting: Jamie's house - a person who was admitted as a prophet and protect women and childrenDr. Foster was investigating his wife about the truth that people were being protected or not)

Dr. Foster: They cannot read, and from what I can tell, they spend all day making crafts for Jamie to sell? Do you think that is healthy?

Jamie's wife: We will take care of our children our way you take care of yours your way. (Scare tone) Dr. Foster: Do you believe that Jamie is a prophet?

Jamie's wife: I was nineteen and a user when I met him. Jamie was handsome, and he cleaned me up. He will keep my kids and I cannot lose my babies. (Uncomfortable tone)

(Lie to Me, "Truth or Consequences", 24:16) 


\begin{tabular}{|c|c|c|c|c|c|}
\hline Speaker & Utterances & QN & QL & RL & $\mathrm{MN}$ \\
\hline Jamie's wife & $\begin{array}{l}\text {-We will take care of our children our way you } \\
\text { take care of yours your way. } \\
\text { - I was nineteen and a user when I met him. Ja- } \\
\text { mie was handsome, and he cleaned me up. He } \\
\text { will keep my kids and I cannot lose my babies. }\end{array}$ & $\begin{array}{l}\sqrt{ } \\
\sqrt{ }\end{array}$ & $\begin{array}{l}\sqrt{ } \\
\sqrt{ }\end{array}$ & $\begin{array}{l}\sqrt{ } \\
\sqrt{ }\end{array}$ & \\
\hline
\end{tabular}

Table 7

Note: $\mathrm{QN}=$ Quantity, $\mathrm{QL}=$ Quality, $\mathrm{RL}=$ Relevant, $\mathrm{MN}=$ Manner

It could be seen clearly that Jamie's wife was telling a lie. She did not do any business with Jamie's work because he afraid to tell the truth, and Jamie would harm her children. As a result, she smoothed a lie by suggesting indirectly stopping asking, 'We will take care of our children our way you take care of yours your way.' This shows that she did uninformative answer, and avoids it that she violated two maxims, the maxim of quantity and maxim of quality. She knew that kids who could not read and made a craft were not healthy, but she covered and distorted it (maxim of quality). Also, she provided irrelevant answer, which is easily can be predicted as a lie, 'I was nineteen and a user when I met him. Jamie was handsome, and he cleaned me up. He will keep my kids and I cannot lose my babies'. She gave detail information about the first she met Jamie, which does not relevant to the Dr. Foster's question. She wanted that Dr. Foster leaves her alone and forget about what was happening in the community. She does not want Dr. Foster knew the truth because her husband would do anything to harm herself and her children. This character showed that she did not violate the maxim of manner as her way to hide the truth.

From seven excerpts above can be concluded that those characters did not violated all the maxims when they were lying. Most of them violated maxim of quantity, quality, and relevance in the same time. Only one from the excerpts violated all the maxims at the same time (see table 5). However, the maxim of manner was rarely being violated because they tried to control and behave when they were lying. It was hard to control a nervous manner towards their lying. If the speaker is violating the maxim of manner, but he or she cannot do it well, the way of hiding the truth can be seen clearly.

\section{CONCLUSION}

The present research analyzed the utterances were used in the five episodes of TV series entitled Lie to Me (2010). The purpose of the research was to reveal the instances of the maxims violation which were used to hide the truth. From the discussion above, it drags a conclusion that in some situations, especially in crime cases, people disobey the Cooperative Principle (Grice, 1975) deliberately. The violation of maxims does not mean that the speaker must be telling lie, but it can also be used as a prediction that the 
speaker may hide something. From that TV series, when the characters noticed that they wanted to be looked for about their involvement toward to the case, the characters began to eliminate any chance for the hearer to respond. As a result, the hearer would not ask more questions, and achieve their goals. Nevertheless, when the characters violated a certain number of maxims, it supposes to be easier for the hearer, especially in crime investigation, to identify that those characters have something to be hidden, since they want to build other's belief. In addition, not all the maxims can be violated in the same time because unconsciously, people have tendency only focus on two or three maxims in the same time when they are lying. From the seven excerpts showed that the maxim of manner is rarely to be violated when people are telling lie. It may be easier to violate the maxim of quality, quantity, and relevance because people may not put much attention to their attitude, and more focus on their utterance.

The Cooperative Principle depicts best theory in order to facilitate process of lie. In Lie to $M e$, as a demonstrated in the study, the characters did multiple violations in every section of investigation. Telling a lie can be a cruel tool at the important situation because it omits major information that is needed. Since the series was based on true characters, the finding is a good capture as the criteria that may happen in the real life. Also, it can be useful for linguistic learner, who is interesting with the Cooperative Principle theory, because language learning should not focus on grammatical competence only, but also communicative competence.

This research only analyzed the utterances in the investigation scenes, hence I suggest that researches in the future who want to analyze the maxims violation may use different scene, but still consists a lie. I hope this analysis can be useful to improve the understanding of the violation of maxims, specifically for lying purposes. In fact, people will be able to see what is behind one's utterance.

\section{BIBLIOGRAPHY}

Jaszczolt, K.M. "Semantics and Pragmatics: The Boundary Issue." University of Cambridge.

http://tu-dresden.de/die_tu_dresden/fakultaeten/philosophische_fakultaet/iph/ thph/braeuer/lehre/bezugnahme_relevanz/Jaszczolt\%20-\%20BoundaryIssue.pdf. Web. 20 September 2013.

$\mathrm{Hu}$, Shuqin. "An Analysis of Humor in the Big BangTheory from Pragmatic Perspectives Qingdao University of Science and Technology." 2012

https://www.google.com/url? sa=t\&rct=j\&q=\&esrc=s\&source=web\&cd=1\& ved $=0 \mathrm{CCgQFjAA \& url=http} \% 3 \mathrm{~A} \% 2 \mathrm{~F} \% 2 \mathrm{Fojs}$.academypublisher.com $\% 2 \mathrm{Findex}$. php \%2Ftpls\%2Farticle\%2Fdownload\%2Ftpls $020611851190 \% 2$ F 4965\&ei= dd4-UoOTKo2JrgfUo4DIAQ\&usg=AFQjCNGSN5_-ak37a0TUVJHvn2Y5d_ VMXA\&bvm=bv.52434380,d.bmk. Web. 19 September 2013 
Dutra, Luiz Henrique De A. "A Pragmatic View of Truth."

Federal University of Santa Catrina. 2001. www.doaj.org. Web. 10 September 2013

Malinowski, Jacek. The pragmatic Interpretation of Utterances.

http://www.home.umk.pl/ jacekm/pragutter.pdf. Web. 19 September 2013

Khosravizade, Parvaneh and NikanSadehvandi. "Some Instances of Violation and Flouting of the Maxim of Quantity bythe Main Characters (Barry \& Tim) in Dinner for Schmucks." Sharif University of Technology. 2011.

http://www.academia.edu/1588301/Some_Instances_of_Violation_and_Flouting_ of_the_Maxim_of_Quantity_by_the_Main_Characters_Barry_and_Tim_in_Dinner_for_ Schmucks. Web. 19 September 2013 